\title{
Allergy to LTP: to eat or not to eat sensitizing foods? A follow-up study
}

\author{
${ }^{1}$ Ambulatorio di Allergologia, Clinica San Carlo, Paderno Dugnano (MI), Italy \\ ${ }^{2}$ UOC Medicina Generale - Immunologia e Allergologia, IRCCS Foundation Ca' Granda Ospedale Maggiore Policlinico, \\ Milan, Italy
}

\section{KEY WORDS}

food allergy; lipid transfer protein; anaphylaxis; oral allergy syndrome; follow-up

\section{Correspondending author}

Riccardo Asero

Ambulatorio di Allergologia

Clinica San Carlo

Via Ospedale 21

20037 Paderno Dugnano (MI), Italy

E-mail: r.asero@libero.it

\section{DOI}

10.23822/EurAnnACI.1764-1489.57

\begin{abstract}
Summary
Background. Follow-up data about the onset of novel food allergies in patients allergic to lipid transfer protein (LTP) are missing. We investigated the occurrence of novel allergies over time in LTP hypersensitive patients. Methods. Sixty-seven LTP-allergic patients recommended to avoid foods responsible for systemic reactions and encouraged to eat other sensitizing foods avoiding the association with known co-factors, were re-evaluated after $\geq 1$ year to assess the occurrence of allergy to novel foods. IgE to rPru $p$ 3, rBet v 1, and r Phl $p 12$ were measured. Results. At baseline, the most frequent offending foods were Rosaceae / Prunoideae, tree nuts, and peanut. Most patients reacted to $>1$ food, and $77 \%$ experienced systemic allergic reactions. Those monosensitized to LTP showed a higher prevalence of food-induced systemic reactions than patients co-sensitized to profilin andlor PR-10 $(p<0.01)$. Baseline Pru $p 3$ IgE levels did not differ between patients with local symptoms or systemic symptoms. 1-16 years after the baseline evaluation 18/67 (27\%) patients had experienced new food allergies; 8 and 10 reported local or systemic symptoms following the ingestion of previously tolerated foods. Again, most new allergies were caused by Rosaceae / Prunoideae, tree nuts, and peanut. The clinical evolution did not depend on baseline total IgE, co-sensitization to PR-10 andlor profilin, or Pru 3 IgE levels. Conclusions. Rosaceae / Prunoideae, nuts and peanut are the most frequent cause of new food allergies in the long term. Their exclusion from patient's diets at baseline should be considered on an individual basis.
\end{abstract}

\section{Introduction}

Nonspecific lipid transfer protein (LTP) is by far the main cause of primary food allergy in Italian adults (1) and generally in the Mediterranean European Countries, and is responsible for the largest number of food-induced anaphylactic reactions as well (2). Due to the widespread distribution of LTP in the plant kingdom, and to the cross-reacting nature of this protein, hypersensitive patients are potentially at risk of experiencing allergic reactions following the ingestion of an array of botanically unrelated fruits and vegetables. However, the clinical expression of LTP hypersensitivity is extremely variable, with many pa- tients that tolerate foods they are strongly sensitized to (3-5), others that react only in the presence of co-factors such as exercise, NSAIDs, or alcoholic beverages, and subjects experiencing severe allergic reactions despite low specific IgE levels. This poses serious ethical problems to doctors dealing with LTP-allergic patients. In fact, whether patients should be advised to avoid all foods to which they are sensitized albeit tolerant, or be recommended to pursue their ingestion, is still undefined. To the best of our knowledge, no follow-up data exist in LTP-allergic patients, in terms of frequency and clinical presentation of novel food allergies over time. The aim of the present study was to investigate in the long term the occurrence of novel plant food 
allergies in LTP-allergic patients, in response to the recommendation to avoid only known offending foods and to continue to eat other plant foods irrespective of sensitization status.

\section{Patients and methods}

\section{Patients}

Sixty-seven subjects $(\mathrm{m} / \mathrm{f} 31 / 36$; mean age at the first visit 33.8 years; range 6-56 years) were included in the present study. All presented spontaneously at one of the two participating allergy centers during the last 16 years due to probable food allergy, and were diagnosed as having LTP allergy based on clinical history and reactivity to SPT with a commercial peach extract (ALK-Abellò) containing $30 \mathrm{mcg} / \mathrm{ml}$ of Pru p 3. Previous studies showed that commercial peach extracts lack the labile allergens Pru p 1 (PR-10) and Pru p 4 (profilin) (6). We also had an in-house purified peach LTP extract prepared by our lab, to use when commercially LTP enriched peach extract or rPru p 3 and other rLTPs were not yet available in ImmunoCAP (7).

At the baseline visit, patients underwent a thorough interview to ascertain all food-induced adverse reactions occurred before. Reported symptoms were classified as local (contact urticaria $[\mathrm{CU}]$, or oral allergy syndrome $[\mathrm{OAS}]$ ) or systemic (urticaria / angioedema or anaphylaxis). OAS was defined as the occurrence of oral itching, with or without angioedema of the lips and/or tongue, a few minutes after the ingestion of an offending food on at least 2 distinct occasions. Patients co-sensitized to PR-10 proteins and/or profilin were also considered allergic to LTP when they had a history of systemic symptoms or, alternatively, of OAS following the ingestion of cooked or industrially processed foodstuff, as it is well known that in such foods labile proteins are no longer allergenic. Systemic reactions were considered as possibly food-induced if they occurred within $2 \mathrm{~h}$ after the ingestion. Hospital and emergency department recordings were analyzed as well, when available. All patients with a history of systemic reaction had already spontaneously withdrawn the putative offending food from their diets at the time of the first visit, whereas those with a history of local reactions were still on a free diet in most cases. At the end of the baseline visit, patients were recommended to go on avoiding the food(s) responsible for systemic reactions, and were encouraged to continue eating all the other sensitizing foods, with the only caveat to avoid the association with known co-factors such as exercise, nonsteroidal anti-inflammatory drugs, and alcoholics. Further, patients were recommended to peel the sensitizing fruits where possible. Patients were left free to stop eating foods causing local symptoms if they induced excessive discomfort.
The effects of such policy were assessed about every year during the follow-up visits, when patients were thoroughly interviewed about their compliance to the prescribed diet regimen and the occurrence of further, new allergic reactions (either local or systemic) to foods that were tolerated before. Hypersensitivity to novel, clinically offending foods was assessed by SPT with commercial extracts and/or fresh material as reported above, if not already detected at the baseline visit.

\section{In vivo-tests}

Along with SPT with the commercial peach extract, SPTs with a standard panel of commercial plant food extracts (ALK-Abellò $1 / 20 \mathrm{w} / \mathrm{v}$ ) including apple, peanut, wheat, soybean, walnut, hazelnut, tomato, carrot, celery, and almond were carried out. Hypersensitivity to reportedly offending foods other than those included in the commercial panel was confirmed by SPT using fresh material by the prick-prick technique.

SPTs were carried out on the volar side of the forearm with a sterile, $1 \mathrm{~mm}$-tip lancet (ALK-Abellò) pricking through the drop of the extract. Readings were taken after $15 \mathrm{~min}$, and results were assessed by established methods (8). A SPT with histamine $10 \mathrm{mg} / \mathrm{ml}$ was carried out as positive control.

\section{In vitro tests}

Serum specific IgE levels to rPru p 3 (the peach LTP), rBet v 1 (the major birch pollen allergen, representative of the cross-reactive PR-10 allergen family), and $\mathrm{r}$ Phl p 12 (grass profilin, as a representative of all homologous allergens) were measured by ImmunoCAP (ThermoFisher Scientific), immediately after the baseline visit or during the follow-up visit when they became commercially available. Values $<0.35 \mathrm{kU} / \mathrm{l}$ were considered negative. Total IgE were measured as well in 21 patients.

\section{Statistics}

Proportions were compared by chi-square test with Yates' correction. Specific IgE levels were compared by two-tailed Student's t-test. Probability values $<0.05$ were considered statistically significant.

\section{Ethics}

Patients gave an informed consent to in vivo and in vitro investigations and to the use of their clinical data for research purposes in an anonymous form. In view of the purely observational nature of the study, along with the fact that all the interventions were part of routine clinical practice, a formal approval by the Ethical Committee was not needed and was not requested. 


\section{Results}

\section{Baseline data}

The baseline clinical features of the study population, along with the offending foods and the clinical characteristics of allergic reactions, are summarized in table I. Specific IgE to rPru p 3 were measured in 65/67 patients, and confirmed LTP sensitization in all cases. rPru p $3 \mathrm{IgE}$ levels ranged from $0.39 \mathrm{kU} / \mathrm{L}$ to $>$ $100 \mathrm{kU} / \mathrm{L}$ (mean $13.02 \mathrm{kU} / \mathrm{L}$ ). Nineteen patients were co-sensitized to PR-10, as shown by $\mathrm{rBet} v \mathrm{IgE}$ levels ranging from 0.65 to $>100 \mathrm{kU} / \mathrm{L}$, and 5 patients were co-sensitized to profilin (IgE to $\mathrm{rPhl} \mathrm{p} 12$ ranging from 0.37 to $>100 \mathrm{kU} / \mathrm{L}$ ). Thirteen further patients were co-sensitized to both PR-10 and profilin. Total $\operatorname{IgE}$ were measured in 21 patients and ranged between 30 and $5000 \mathrm{kU} / \mathrm{L}$.

At the baseline visit, the most frequently reported offending foods belonged to the Rosaceae / Prunoideae family (peach, apricot, plum, cherry, apple, pear, loquat, almond) and caused clinical symptoms in a total of $48(71 \%)$ patients, specifically oral allergy syndrome in 34 subjects, urticaria in 12 , contact urticaria in 8 , gastrointestinal symptoms in 2 , anaphylaxis in 7 cases, and FDEIA in 3. Tree nuts $(\mathrm{n}=34$ [51\%]) and peanut $(\mathrm{n}=13[19 \%])$ were also a frequent cause of food-induced symptoms, whereas other fruits and vegetables such as tomato, onion, citrus fruits, legumes, pesto sauce, beer, grapes, Brazil nut, lettuce, broccoli, and others were less frequently involved (table I). Most patients experienced allergic reactions following the ingestion of more than one LTP-containing plant-derived food on different occasions. The peach was by far the most frequent cause of contact urticaria $(n=7)$, the other two cases being associated with apple and rice, respectively.

Fifty-two (77\%) patients experienced systemic symptoms (urticaria / angioedema, anaphylaxis, or FDEIA) following the ingestion of offending foods. Again, Rosaceae / Prunoideae, tree nuts and peanut were by far the most frequent offenders. Other foods inducing systemic reactions in $>2$ patients included tomato, lettuce, beer, onion, and grapes. Tree nuts $(n=9)$ and peanut $(n=8)$ were the foods most frequently causing anaphylactic reactions while, surprisingly enough, tomato was the food most frequently involved in FDEIA $(n=4)$. The LTP reactivity to tomato was confirmed by the prick-prick technique, using a commercially available triple concentrate tomato paste or by skin prick test with an in house tomato extract, obtained from triple concentrate commercially available tomatoes (9).

In view of the high prevalence of co-sensitization to PR-10 and/ or profilin, the 30 patients monosensitized to LTP were analyzed separately, and grouped on the basis of the clinical symptoms and not of the various foods they were allergic to, as these could induce clinically different symptoms. In this subset, 5
Table I - Main baseline features of 67 patients allergic to LTP.

\begin{tabular}{|c|c|}
\hline age (mean and range) & $33.8(6-56)$ yrs \\
\hline gender $\mathrm{m} / \mathrm{f}$ & $31 / 36$ \\
\hline \multicolumn{2}{|l|}{$\begin{array}{l}\text { Sensitization status } \\
\end{array}$} \\
\hline monosensitized to LTP & 30 \\
\hline co-sensitized to PR-10 only & 19 \\
\hline co-sensitized to profilin only & 5 \\
\hline co-sensitized to both PR-10 and profilin & 13 \\
\hline \multicolumn{2}{|l|}{ Clinical food allergy } \\
\hline local symptoms only & 15 \\
\hline local + systemic symptoms & 35 \\
\hline systemic symptoms only & 17 \\
\hline \multicolumn{2}{|l|}{ Offending foods } \\
\hline Rosaceae / Prunoideae & 48 \\
\hline tree nuts & 34 \\
\hline peanut & 13 \\
\hline other legumes (pea, beans, lupine, soybean) & 6 \\
\hline tomato & 13 \\
\hline lettuce, chicory, rucola, etc. & 8 \\
\hline fennel & 6 \\
\hline kiwi & 5 \\
\hline melon, watermelon & 4 \\
\hline zucchini & 1 \\
\hline rice & 3 \\
\hline maize & 1 \\
\hline wheat, barley & 3 \\
\hline beer & 3 \\
\hline onion & 4 \\
\hline citrus fruits & 3 \\
\hline spinach & 3 \\
\hline sesame seed, poppy seed, sunflower seed & 4 \\
\hline parsley & 1 \\
\hline carrot & 3 \\
\hline broccoli & 1 \\
\hline banana & 1 \\
\hline commercial pesto sauce & 2 \\
\hline eggplant & 2 \\
\hline grapes, wine & 3 \\
\hline cashew & 1 \\
\hline pineapple & 1 \\
\hline bell pepper & 1 \\
\hline fig & 1 \\
\hline saffron & 1 \\
\hline
\end{tabular}


(17\%) experienced contact urticaria, $15(50 \%)$ oral allergy syndrome, 3 (10\%) gastrointestinal symptoms, 12 (40\%) urticaria I angioedema, 13 (43\%) anaphylaxis, and 7 (23\%) FDEIA following the ingestion of one or more plant foods. Also among LTP mono-reactors, the members of the Rosaceae / Prunoideae family caused the majority of adverse reactions: contact urticaria in $4 / 5$ patients, OAS in $13 / 15$, urticaria in $6 / 12$, anaphylaxis in $5 / 13$, and FDEIA in 2/7. Again, tree nuts were the second most relevant cause of anaphylaxis $(n=4)$ and FDEIA $(n=2)$.

Comparing mono-sensitized with co-sensitized patients, no difference in mean age and gender was observed; the former showed a slightly higher prevalence of food-induced systemic reactions (i.e., urticaria / angioedema, anaphylaxis, and/or FDEIA): $24 / 30(80 \%)$ vs $22 / 37(59 \%)$, respectively ( $\mathrm{p}=\mathrm{NS}$ ). Interestingly, the higher prevalence of systemic reactions in the former subgroup occurred despite significantly lower mean levels of IgE to rPru p 3: $7.06 \pm$ SD $7.04 \mathrm{kU} / \mathrm{L}$ vs $17.11 \pm 20.8$ $\mathrm{kU} / \mathrm{L}$, respectively $(\mathrm{p}<0.01)$. Offending foods did not differ significantly between the two subgroups.

Both median and mean rPru p 3 IgE levels did not differ between patients with local symptoms only $(14.4 \mathrm{kU} / \mathrm{L})$ and patients reporting systemic symptoms ( $12.3 \mathrm{kU} / \mathrm{L})$.
Baseline total $\mathrm{IgE}$ levels did not influence the prevalence of systemic or local food-induced symptoms. No correlation was found between total $\operatorname{IgE}$ and specific IgE levels for raw foods or specific recombinant molecules.

\section{Follow-up data}

The follow-up visits were performed every 12-18 months after the baseline evaluation. At that time point $47 / 67$ (70\%) patients were unchanged (i.e., did not experience any allergic reaction to foods they were sensitized to but tolerated when the baseline visit was performed). Two other patients experienced urticaria and urticaria + shortness of breath, respectively, following the inadvertent ingestion (in one case associated with exercise) of cookies containing tree nuts, but these foods had already been involved in systemic reactions before.

In total, 18/67 (27\%) patients reported new food allergies (table II). Of these, 9 (47\%) were monosensitized to LTP and 9 co-sensitized to PR-10 and/or profilin. Eight patients reported local symptoms only (OAS in 7 cases, gastrointestinal in 1 case) following the ingestion of rice (3 cases), strawberry, walnut, kiwi, maize, zucchini, raw fennel, chestnut, lettuce, and string

Table II - Allergic reactions and offending foods in 18 patients experiencing allergies to new foods during the follow-up period.

\begin{tabular}{|c|c|c|c|c|}
\hline Phl p 12 & Bet $\mathbf{v} 1$ & Follow-up (yrs) & Local & Systemic \\
\hline 2.06 & neg & 3 & strawberry & \\
\hline 3.39 & 6.75 & 6 & & peeled peach \\
\hline 8.54 & 4.67 & 3 & & saffron \\
\hline neg & neg & 4 & tomato, fennel, apple & onions, pistachio \\
\hline neg & neg & 2 & walnut, kiwi & \\
\hline neg & neg & 5 & & apple juice \\
\hline 18.6 & 23.1 & 8 & rice & \\
\hline neg & neg & 7 & popcorn & almond milk, rice + saffron \\
\hline neg & neg & 12 & lettuce, walnut, pineapple, rice & plum, cherry \\
\hline neg & neg & 2 & rice, maize & \\
\hline neg & 2.70 & 3 & rice, zucchini & \\
\hline neg & 12.10 & 8 & fennel & \\
\hline neg & 21.70 & 7 & lentil & pistachio \\
\hline neg & neg & 1 & & walnut \\
\hline neg & 64.30 & 10 & chestnut & \\
\hline neg & neg & 7 & & kiwi \\
\hline 0.50 & 7.41 & 8 & & broccoli, mandarin \\
\hline neg & neg & 10 & lettuce, string beans & \\
\hline
\end{tabular}


beans. Four patients reported OAS from more than 1 previously tolerated food. Ten patients experienced systemic symptoms following the ingestion of previously tolerated foods including peeled peach, saffron ( 2 cases), onion, pistachio ( 2 cases), apple juice, almond milk, rice, plum, cherry, walnut, kiwi, broccoli, and mandarin. These 10 patients reported also novel local symptoms following the ingestion of tomato, fennel, popcorn, lettuce, walnut, pineapple, rice, and lentil. Anaphylactic reactions to new foods occurred only in 2 cases, and in both of them were induced by pistachio nut, but, notably, one patient turned out to be co-sensitized to seed storage proteins.

The clinical evolution did not depend on the baseline total IgE level, and the presence / absence of co-sensitization to PR-10 and/or profilin did not influence the probability of allergic reactions to new foods, nor the severity of such reactions. Baseline rPru p $3 \mathrm{IgE}$ levels, as well as $\mathrm{IgE}$ to $\mathrm{rBet} 1$ or $\mathrm{rPhl} \mathrm{p} 12$, did not differ statistically between patients developing or not developing new food allergies (data not shown). Further, the two populations did not differ in terms of age and gender.

\section{Discussion}

In recent years, many studies of specific oral tolerance induction / oral immunotherapy (SOTI/OIT) have been carried out, mainly in patients with severe allergy to milk, egg, or peanut. Despite the substantial risk of adverse events, the results of these procedures suggest that the introduction of gradually increasing amounts of the relevant foods followed by their ongoing ingestion is able to push up significantly and steadily patients' tolerance threshold (at least until the food is eaten on a regular basis), thus reducing the risk associated with the inadvertent ingestion of limited amounts of the allergen protein(s) (10). In the case of allergy to lipid transfer protein, Spanish and Portuguese researchers have attempted to desensitize allergic patients by the administration of repeated, known amounts of Pru $\mathrm{p}$ 3 through sublingual route, apparently with good results (1113). Both oral and sublingual immunotherapy have still to be considered experimental treatment strategies to reduce the food allergic status, and cannot be practiced on a routine basis in the clinic. However, based on all these observations and in view of the widespread diffusion of lipid transfer protein in the plant kingdom, and of the high degree of cross-reactivity within this protein family, we hypothesized that encouraging LTP allergic patients to go on eating all foods containing LTP they were sensitized to, and that had been tolerated until the first visit, might be a safer and more feasible policy than the strict avoidance of such foods, a policy that in some cases would have meant to exclude virtually all plant-derived foods from the diet with the possible exception of carrot and a few other items (14). In other words, we thought that this approach could work as a sort of "natural, attenuated oral immunotherapy" able to maintain a state of oral tolerance to specific foods by preventing a gradual decrease of the provocation threshold dose without the risks associated with an oral / sublingual immunotherapy with Pru p 3 , the LTP that causes clinical allergy in virtually all patients. Of course, for safety reasons, patients were also recommended to avoid well known co-factors, particularly exercise (15), following the ingestion of all foods they were sensitized to.

At the follow-up visit, more than one fourth of the study population reported allergic reactions induced by foods that were previously tolerated, and in more than one half of such cases reactions were systemic and associated with an array of botanically unrelated foods. Notably, most new reactions were associated with Rosaceae / Prunoideae (peeled peach, apple juice, plum, cherry, and almond milk) and with tree nuts (walnut and 2 cases from pistachio nut, the latter inducing the only two anaphylactic reactions recorded, one of whom was eventually found to have become positive to storage protein as well). Regarding symptoms associated with peeled peach, we miss the information about how it was peeled; in fact, the use of a very sharp knife makes the association with Pru p 7 (the peach peamaclein) sensitization more likely, whereas a less accurate peeling could be in effect associated with Pru p 3 exposure. Similarly, regarding almond milk, we could hypothesize a contamination by almond peel, otherwise seed storage proteins become a more likely candidate as the cause of adverse reactions.

Interestingly, saffron appeared as an emergent cause of allergic reactions in LTP-hypersensitive subjects, possibly because in the Italian cuisine it is eaten in most cases in conjunction with rice, another potentially offending food for LTP sensitized patients $(16,17)$, thus resulting in an additive provocation. In fact, these patients were able to tolerate the rice if it was eaten alone or with foods other than saffron (e.g., mushrooms).

Based on the findings of the present study it might seem reasonable to recommend LTP reactors to avoid strictly all members of the Rosaceae / Prunoideae family (with the possible exception of the pear as previous, unpublished studies from our group show that this fruit contains very small amounts of the protein), if the baseline in-vivo tests with fresh material suggest sensitization. Similarly, it might be the case to recommend the avoidance of tree nuts of different sorts, as well as peanuts, when the patient shows cross-sensitization, as these fruits are associated with particularly severe reactions. On the other hand, it has to be considered that only a minority of our patients developed new food allergies during the follow-up period, and that in the majority of cases these were represented by local reactions. Since we were not able to detect any predictive factor (neither specific IgE-level, nor monosensitivity or co-sensitization) it is likely that the decisions regarding the exclusion of certain foods have to be taken on an individual basis, taking into account the quality of life of the patient as well as the severity of prior reactions with other foods. 
We are aware that our study shows some evident limitations. First, with such a study design the degree of exposure to LTPs contained in foods other than the offending ones cannot be assessed in individual patients and, even if the exposure occurred on a regular basis, its amount may have varied from one patient to another. Second, since a control group is missing, we are unable to state which the consequences would have been if the same individuals were advised to strictly avoid exposure. However, as noted before, it should be considered that the strict avoidance of all sensitizing foods would have heavily worsened the quality of life of a number of control patients on one side, and would have eventually led to the necessity to perform open oral food challenges with all the excluded (but previously tolerated) foods in the clinics and under medical supervision, in order to assess their tolerance after a long period of avoidance, on the other side. Alternatively, creating a different control group left at a free diet (i.e., not excluding known offending foods) without giving any clinical advice, would have exposed the members to severe risks of adverse events, which is unethical, and most probably patients in such a group would have eventually behaved as our current study group, that is avoid all offending foods and going on eating the tolerated ones. Third, the study is based on patients' reports, and these were not confirmed by properly performed oral challenges. Bias may have been introduced for reactions that occurred long time before regarding the presence or absence of co-factors. Finally, the possibility that sensitization to other allergens (e.g., seed storage proteins such as 2 -albumins, vicilins or legumins, or alternatively pollen-associated allergens such as PR-10 molecules or profilin) was responsible for the novel allergies reported by the patients should be taken into consideration. However, although in effect one patient with a novel pistachio allergy was eventually found to be neo-sensitized to a seed storage protein, in most cases adverse reactions were associated with Rosaceae / Prunoideae, a group of fruits that lack seed storage proteins, which makes this hypothesis unlikely. Further, no patient who experienced allergic reactions to novel foods developed a new sensitization to birch pollen or profilin. The present study confirms the protective effect of co-sensitization to PR-10 and/or profilin against severe adverse reactions induced by offending foods in LTP-hypersensitive subjects (18). In fact, despite significantly higher levels of IgE to rPru p 3, co-sensitized patients showed a much lower propensity to experience systemic allergic reactions following the ingestion of offending foods. Previous studies found a direct association between high rPru p 3 IgE levels and the probability to react to a large array of botanically unrelated foods (19), but of course those studies were carried out on LTP-monosensitive patients, whereas the large majority of the patients in the present study were co-sensitized to PR-10 and/or profilin. This study also shows that allergy to lipid transfer protein probably represents the most difficult type of food allergy, in terms of preventive strategies. The widespread diffusion of the protein, along with its variable degree of cross-reactivity from one patient to another, make it virtually impossible to predict which foods the patients will react to, and which will be the clinical expression of such adverse events, with the exception of the peach, that is the primary sensitizer to LTP and represents the food most frequently responsible for allergic reactions $(1,20)$.

In conclusion, this study shows that Rosaceae / Prunoideae (with the possible exception of pear and peeled apple), tree nuts and peanuts, are the most frequent cause of new allergic reactions in the long term in LTP-allergic patients that are sensitized but clinically tolerant to these foods. In view of the limited prevalence of new allergic reactions, and of the fact that these are frequently local, the decision regarding their preventive avoidance have to be taken on an individual basis until larger prospective studies are carried out. Regarding the other foods that induced adverse reactions, these events occurred in a minority of sensitized subjects, and such a low prevalence does not seem to justify their exclusion from patients' diets.

\section{Conflict of interest}

The authors declare that they have no conflict of interest.

\section{References}

1. Asero R, Antonicelli L, Arena A, et al. EpidemAAITO: features of food allergy in Italian adults attending allergy clinics: a multicentre study. Clin Exp Allergy 2009; 39:547-55.

2. Asero R, Antonicelli L, Arena A, et al. Causes of food-induced anaphylaxis in Italian adults: a multicentre study. Int Arch Allergy Immunol 2009; 150:271-7.

3. Rodriguez J, Crespo JF, Lopez-Rubio A, De La Cruz-Bertolo J, Ferrando-Vivas P, Vives R, Daroca P. Clinical cross-reactivity among foods of the Rosaceae family. J Allergy Clin Immunol 2000; 106:183-9.

4. González-Mancebo E, González-de-Olano D, Trujillo MJ, Santos S, Gandolfo-Cano M, Meléndez A, Juárez R, Morales P, Calso A, Mazuela O, Zapatero A. Prevalence of sensitization to lipid transfer proteins and profilins in a population of 430 patients in the south of Madrid. J Investig Allergol Clin Immunol 2011; 21:278-82.

5. Pascal M, Vazquez-Ortiz M, Folque MM, Jimenez-Feijoo R, Lozano J, Dominguez O, Piquer-Gibert M, Giner MT, Alvaro M, Dias da Costa M, García-Paba B, Machinena A, Alsina L, Yagüe J, Plaza-Martin AM. Asymptomatic LTP sensitisation is common in plant-food allergic children from the Northeast of Spain. Allergol Immunopathol (Madr) 2016; 44:351-8.

6. Asero R. Detection and clinical characterization of patients with oral allergy syndrome caused by stable allergens in Rosaceae and nuts. Ann Allergy Asthma Immunol 1999; 83:377-83.

7. Pastorello EA, Farioli L, Pravettoni V, Ortolani C, Ispano M, Monza M, Baroglio C, Scibola E, Ansaloni R, Incorvaia C, Conti A. The major allergen of peach (Prunus persica) is a lipid transfer protein. J Allergy Clin Immunol 1999; 103:520-6. 
8. Dreborg S, Frew A. Allergen standardization and skin tests. EAACI position paper. Allergy 1993; 48:49-75.

9. Pravettoni V, Primavesi L, Farioli L, Brenna OV, Pompei C, Conti A, Scibilia J, Piantanida M, Mascheri A, Pastorello EA. Tomato allergy: detection of IgE-binding lipid transfer proteins in tomato derivatives and in fresh tomato peel, pulp, and seeds. J Agric Food Chem 2009; 57:10749-54.

10. Burbank AJ, Sood P, Vickery BP, Wood RA. Oral immunotherapy for food allergy. Immunol Allergy Clin N Am 2016; 36:55-69.

11. Fernández-Rivas M, Garrido Fernández S, Nadal JA, Díaz de Durana MD, García BE, González-Mancebo E, Martín S, Barber D, Rico P, Tabar AI. Randomized double-blind, placebo-controlled trial of sublingual immunotherapy with a Pru p 3 quantified peach extract. Allergy 2009; 64:876-83.

12. Pereira C, Bartolomè B, Asturias JA, Ibarrola I, Tavares B, Loureiro G, Machado D, Chieira C. Specific sublingual immunotherapy with peach LTP (Pru p 3). One year treatment: a case report. Cases Journal 2009; 2:6553.

13. Gomez F, Bogas G, Gonzalez M, Campo P, Salas M, Diaz-Perales A, Rodriguez MJ, Prieto A, Barber D, Blanca M, Torres MJ, Mayorga C. The clinical and immunological effects of Pru p 3 sublingual immunotherapy on peach and peanut allergy in patients with systemic reactions. Clin Exp Allergy 2017; 47:339-50.

14. Asero R, Mistrello G, Roncarolo D, Amato S. Detection of some safe plant-derived foods for LTP-allergic patients. Int Arch Allergy Immunol 2007; 144(1):57-63
15. Romano A, Scala E, Rumi G, Gaeta F, Caruso C, Alonzi C, Maggioletti M, Ferrara R, Palazzo P, Palmieri V, Zeppilli P, Mari A. Lipid transfer proteins: the most frequent sensitizer in Italian subjects with food-dependent exercise-induced anaphylaxis. Clin Exp Allergy 2012; 42:1643-53.

16. Asero R, Amato S, Alfieri B, Folloni S, Mistrello G. Rice: another potential cause of food allergy in patients sensitized to lipid transfer protein. Int Arch Allergy Immunol 2007; 143:69-74.

17. Pastorello EA, Scibilia J, Farioli L, Primavesi L, Giuffrida MG, Mascheri A, Piantanida M, Mirone C, Stafylaraki C, Violetta MR, Nichelatti M, Preziosi D, Losappio L, Pravettoni V. Rice allergy demonstrated by double-blind placebo-controlled food challenge in peach-allergic patients is related to lipid transfer protein reactivity. Int Arch Allergy Immunol 2013; 161:265-73.

18. Pastorello EA, Farioli L, Pravettoni V, Scibilia J, Mascheri A, Borgonovo L, Piantanida M, Primavesi L, Stafylaraki C, Pasqualetti S, Schroeder J, Nichelatti M, Marocchi A. Pru p 3-sensitised Italian peach-allergic patients are less likely to develop severe symptoms when also presenting IgE antibodies to Pru p 1 and Pru p 4. Int Arch Allergy Immunol 2011; 156: 362-72.

19. Asero R, Mistrello G, Roncarolo D, Amato S. Relationship between peach lipid transfer protein specific IgE levels and hypersensitivity to non-Rosaceae vegetable foods in patients allergic to lipid transfer protein. Ann Allergy Asthma Immunol 2004; 92:268-72.

20. Asero R. In patients with LTP syndrome food-specific IgE show a predictable hierarchical order. Eur Ann Allergy Clin Immunol 2014; 46:142-6. 